\title{
Marcuse e o homem unidimensional: pensamento único atravessando o Estado e as instituições
}

\author{
Rogério Lustosa Bastos \\ Universidade Federal do Rio de Janeiro (UFRJ)
}

Marcuse e o homem unidimensional: pensamento único atravessando o Estado e as instituições Resumo: O presente artigo, baseando-se em Marcuse, critica a atual globalização e sua rubrica a um modelo dito consensual aos valores do mercado, o homem unidimensional. Este, pretendendo ser o pensamento único, se firmará não só por ditar as condições concretas e subjetivas para todos, mas também por reproduzi-las pelo Estado, notadamente, através das instituições sociais que, apresentando-se como uma rede hegemônica, tenderão a reproduzir essa unidimensionalidade pelo planeta. Sob tempos de quase absoluto consenso em prol desses valores, o artigo reflete sobre as possíveis rupturas ao referido modelo.

Palavras-chave: Subjetividade capitalista. Homem unidimensional. Rede de instituições.

Marcuse and the One-Dimensional Man: One-dimensional thinking in the State and Institutions Abstract: This article, based on Marcuse, criticizes the current movement of globalization and its sustenance of a model considered consensual to market values, the one-dimensional man. This, with the intention of being the sole form of thinking, establishes itself not only by determining the concrete and subjective conditions for everyone, but also by reproducing them through the State, notably, through social institutions that, by presenting themselves as part of a hegemonic network tend to reproduce this one dimensionality throughout the planet. Under times of near absolute consensus in support of these values, the article reflects on possible breaks in this model. "

Keywords: Capitalist subjectivity. One-dimensional man. Institutional network. 


\section{Introdução}

Benjamin (1998) argumenta que sob a égide capitalista, estamos diante de duas categorias principais: a dos vitoriosos e a dos fracassados. Os primeiros, julgando alçar o lugar mais invejado do planeta, empenhamse tanto por chegar ali que até sem perceber, acabam se aprisionando, submetendo-se totalmente ao "partido único dos negócios". Os taxados de fracassados, após descerem ao chão dos desafortunados e depois de analisarem criticamente a sua situação frente ao real, têm grandes chances de se reinventarem de forma diversa a essa "servidão voluntária" aos valores da ordem. Esta, além de naturalizar tudo e todos aos seus valores, entre outros absurdos, diz: "Fora do mercado não há salvação".

Isso implica principalmente que, para Marcuse, sob o atual capitalismo, nos submetemos a um modo de vida de consenso dito inquestionável aos valores do mercado, bem como esse fato é sinônimo de vivermos sob o domínio do homem unidimensional, o qual subscreve as condições materiais e subjetivas para todo o planeta. Apresentando de outro modo, presentemente, o homem unidimensional não só avançou sobre todas as fronteiras com seu modelo econômico que dita as condições materiais, como também agora tem a pretensão de ocupar o território da subjetividade, colonizando-nos a partir da vida simbólica. Este procedimento, de acordo com Marcuse, pode ser estudado através das pulsões freudianas na sua interação com a cultura vigente. A partir disto, nos depararemos com uma série de conceitos, os quais, sob a ordem presente, ganham sentido peculiar em prol do capital: referimo-nos, entre outros exemplos, ao conceito de princípio de realidade, o qual, sob os interesses da cultura de consumo, destaca-se como princípio de desempenho e passa a reger as pulsões sob essa égide. Este fato é um, entre outros procedimentos importantes, que atestam que ao se debruçar sobre a subjetividade, a ordem hegemônica produz a subjetividade dita dominante. Evidentemente, ela não só deve preponderar e se opor sobre as demais, como também facilitar o avanço da unidimensionalidade em discussão, tanto através do desejo inconsciente e da vida simbólica dos indivíduos, quanto na parceria com as instituições sociais.

Essas são algumas das questões que atravessam este artigo cuja pretensão é debater o capitalismo atual, segundo a crítica de Marcuse, ao dito consenso em prol do modo de vida da presente globalização mercadológica cujo modelo é o homem unidimensional. Este, expandindo-se de forma nem sempre visível para todos, tende a se reproduzir através das diferentes instituições sociais. Outro detalhe: é também significativo observar que essa unidimensionalidade ainda se expandirá pela aliança com a tecnologia e a cultura do capitalismo avançado. Enfim, a partir disto, em nome de se aderir a uma visão mais racional e tecnológica, a referida unidimensionalidade se estenderá sobre os diferentes cantos do planeta. Mas, ao pretender ter o controle absoluto de tudo e de todos, expandindo-se sem limites tanto pelo mundo dos negócios e dos lucros, quanto pelo território da subjetividade com "tecnologias próprias para o lado subjetivo", capturando as oposições e os ditos movimentos de emancipação, essa ordem acaba se mostrando com forte tendência totalitária - fato questionado por Marcuse.

Para desenvolver essa crítica, este artigo se apresentará da seguinte forma: na primeira sessão, $\mathrm{O}$ homem unidimensional e a globalização pelo mercado, debateremos tanto o conceito quanto as principais questões envolvendo a não é que o trabalho da ideologia sobre as necessidades reais ou fictícias deixe de ser importante, porém, quando entra em cena a subjetividade hegemônica, há um aprimoramento da eficácia da unidimensionalidade, já que, inconscientemente, será o próprio indivíduo que terá prazer em desejar e servir ao capital. unidimensionalidade do capitalismo tardio (subjetividade, tecnologia, avanços com tendência totalitária desse modelo etc.). Na segunda sessão, Instituição, globalização e o homem unidimensional, se pensará a instituição tanto em seus principais conceitos, quanto também na sua forma de se apresentar por uma rede de poder transversal que atravessa todos os grupos sociais, nas mais diversas sociedades globalizadas. Ora, tendo como modelo o homem unidimensional, essa rede de poder institucional o reproduz em escala internacional. Desta maneira, ela não só se apresentará com a pretensão de exercer um controle sobre possíveis diferenças que queiram destoar, como também reinará de forma hegemônica em todos os lugares, ou seja, ocorrerá aqui a captura dos próprios movimentos ditos de oposição e também dos que se mostram como libertários. Por fim, nas conclusões, entre outros pontos, será ressaltado que há possibilidades de criar resistência a tal modelo de 
pretensões totalitárias, bem como, essas resistências, além de históricas, emergirão dentro das instituições sociais, trazendo à tona as lutas de classe.

\section{0 homem unidimensional e a globalização pelo mercado}

O homem unidimensional, para Marcuse (1982), refere-se principalmente a um modo de vida condizente com o capitalismo vigente e também se expande de forma consensual e com grande tendência totalizante pelo tecido social: de um lado, esse "homem" faz avançar os pressupostos do mercado pelo território econômico, social, político, cultural, científico, tecnológico etc. De outro, avança ainda pelo território subjetivo, notadamente pela produção do desejo inconsciente. Daí que essa "unidimensionalidade" está atualmente pelos quatro cantos do planeta: ela está praticamente em todos os lugares e em lugar algum.

Antes de passarmos à discussão propriamente dita do homem unidimensional, faz-se necessário observar a questão da subjetividade em Marcuse (1981, 2001), a partir do pensamento freudiano. Assim, vejamos tal fato pelo debate de alguns pontos principais: a) ao se deparar com o impasse de que, até então, todas as revoluções fracassaram, Marcuse, além de basear-se em Marx, debruça-se sobre Freud no que se refere particularmente ao estudo das pulsões de Eros e Tanatos em sua relação com a cultura da ordem hegemônica. Diante disto, o filósofo de Frankfurt descobre que a dominação também pode ocorrer pelo estudo da subjetividade, especialmente criando uma que seja favorável ao domínio do capital (há a dominação econômica e política, mas também a dominação intrapsíquica); b) Neste sentido, há todo um trabalho feito em cima da nossa subjetividade, que pode ser traduzido no seguinte: partindo do pressuposto que nossas pulsões vivem em função do prazer e que elas, para que não destruam a nós mesmos e ao outro, necessitam se submeter às coibições culturais; considerando que essa submissão se dá, sobretudo, em nome de se construir uma saída estruturante para elas (basta lembrar que uma existência sem prazer, seria uma vida sem tais pulsões, fato insustentável para qualquer ser humano. Pensando em Eros, por exemplo, se ele não existisse em nossas vidas, estaríamos de fato a mercê de uma existência em que não conseguiríamos de forma alguma criar qualquer sentido). Enfim, diante disto, cria-se todo um processo de coibições sobre essas pulsões, fato que o autor da psicanálise interpreta como algo necessário para a nossa estrutura; c) Mas há aqui uma questão: o problema fica além do necessário quando essas limitações são mescladas com os valores do mercado. A partir disto, vemos uma série de conceitos freudianos sendo capturados pela ordem capitalista, de maneira que o considerado indivíduo saudável tenha como parâmetro os valores de sucesso da sociedade de consumo. Para termos uma visão mais nítida, entre outras ilustrações, vejamos: aqui o conceito de "repressão" ou o recalque (fator necessário para freiar as pulsões e também para submetê-las aos limites sociais, os quais se iniciam com a lei simbólica), esse conceito, como se dizia, agora sob a ordem do capitalismo atual, se torna a "mais repressão"; o "princípio de realidade", seguindo o mesmo caminho, o "princípio de desempenho". Este, sobretudo, ajudará a ordem a estipular metas e a desenvolver no sujeito a dita competitividade, bem como "valores" que têm menos relação com uma estrutura livre e autônoma e mais com as metas e ideais da sociedade do mercado.

Marcuse se opõe veemente a isso e faz uma releitura dos pressupostos freudianos em prol de se criar uma sociedade que rompa com a exploração capitalista, gestando um novo princípio de realidade. Assim, observemos um texto ilustrativo: "Produtividade para quê? A resposta invariavelmente é clara: para satisfazer as necessidades, evidentemente. (...) Mas quando o conceito de necessidades engloba tanto alimentação, roupa, moradia, quanto bombas, máquinas de caça níqueis e a destruição de produtos vendáveis, então podemos afirmar (...) que (esse) conceito é tão desonesto quanto inútil para determinar o que seria produtividade legítima (...). Parece que a produtividade é cada vez mais um fim em si mesmo, e a pergunta sobre a sua utilização não só permanece em aberto, como é cada vez mais recalcada (MARCUSE, 2001b, p. 115-116).

O filósofo ainda defende que o avanço da unidimensionalidade ocorre não às escondidas, mas à luz do dia, sobretudo, por um trabalho de retransmissão social peculiar: através da rede de instituições sociais. Tal rede, afora "retransmitir" a ideologia que tece "maquiagem" entre as "necessidades básicas" e as "necessidades não básicas", agora, visando a hegemonia mais totalizante, transmite um modelo que se inicia a partir da vida simbólica ou de uma produção da subjetividade que interfere em um ponto mais "visceral" para o indivíduo: sua produção de desejo inconsciente. Em outras palavras, não é que o trabalho da ideologia sobre as necessidades reais ou fictícias deixe de ser importante, porém, quando entra em cena a subjetividade hegemônica, há um aprimoramento da eficácia da unidimensionalidade, já que, inconscientemente, será o próprio indivíduo que terá prazer em desejar e servir ao capital. Obviamente, tudo isto ocorrerá através das instituições, ou seja, entrará em cena a instituição da família, a instituição de educação, de trabalho e assim por diante. Desta forma, cada indivíduo "aprenderá" a seguir o modelo de uma vida dita feliz dentro da sociedade de consumo'. 
Antes de discutirmos a sociedade unidimensional através das instituições, vejamos três características básicas dessa sociedade ${ }^{2}$ : 1) Para Marcuse (1981, 1982, 1999), a sociedade globalizada é a do homem unidimensional e também da sociedade tecnológica avançada. Portanto, apesar da automação e da tecnologia atual nos dar condições para romper com o trabalho alienado, infelizmente é o contrário que se vê: a globalização lança mão desses fatores e exerce um controle poderoso sobre os diferentes indivíduos; aqui, presentemente, não só há um elevado nível de automação ou de tecnologia, como também há sutil mecanismo de domínio. Enfim, a rigor, ao aderirmos a esse "modo de vida", nos submetemos a uma racionalidade tecnológica com forte pendor totalitário3:

Atualmente, o poder político se afirma através dos seus poderes sobre o processo mecânico e sobre a organização técnica do aparato. O governo de sociedades industriais desenvolvidas e em fase de desenvolvimento só se pode manter e garantir quando mobiliza, organiza e explora com êxito a produtividade técnica, científica e mecânica à disposição da civilização industrial (MARCUSE, 1982, p. 25).

2) Tendência totalitária? Que tendência totalitária? Esta segunda característica da sociedade unidimensional, sobretudo, pode ser vista na dita forma suave de se exercer o poder. Ora, considerando que são os pressupostos básicos do mercado que interessam, visando que tudo e todos se transformam em mercadorias, tais pressupostos, sob a égide da ordem atual, passam a ser à base de qualquer racionalidade do mundo globalizado. Esta racionalidade hegemônica, aliada ao desenvolvimento tecnológico e científico, avançando sobre os diferentes indivíduos e grupos, apresenta-se como a suposta "verdade" e também age atualmente como se fosse o dito "santo ofício" dos tempos modernos: afora condenar tudo o que não lhe é espelho, discrimina e põe à margem todos os que não se enquadram nos seus pressupostos. Em outros termos, esse poder dito consensual ou racionalidade unidimensional não só é exercido através das redes das instituições sociais e de todo aparato tecnológico daí decorrente, mas também dentro de um modo de se proceder que é cotidianamente paradoxal: quando o domínio em questão é exercido até mesmo para controlar as relações sociais, usa-se e se incentiva a liberdade, mas na realidade só se permite que haja uma suposta liberdade para beneficiar o mercado; quando se defende a livre manifestação nas artes e a na própria vida cultural, tal procedimento é estimulado, mas desde que, sob qualquer hipótese, não se ponha em risco a economia globalizada 4 .

3) A aliança da sociedade unidimensional com a cultura e a arte: isto é fator significativo para a hegemonia da ordem em questão. Dentre os vários motivos, destacamos: (3.1) se outrora a cultura e a arte eram lugares que, a priori, traziam um potencial de rupturas, sob a ordem atual e a partir dessa aliança, o quadro ganha sentido inverso: agora cultura e arte, salvando raras exceções, a princípio, são as maiores aliadas em prol do comércio e do comercial. Em suma, trata-se de uma produção desses dois territórios que acaba sendo reduzida a mera indústria cultural: "Cultura e arte só se destacam aqui se forem um bom negócio"5. (3.2) quando a cultura e a arte são reduzidas ao mero produto, lamentavelmente elas não só fazem com que o homem se identifique com as mercadorias/marcas, como também contribui para perderem seu potencial protagonista/revolucionário para os interesses das mega empresas, que é o lucro. Enfim, quando a ordem do capital chega à subjetividade humana, submetendo os processos inconscientes do desejo ao interesse do capital, apesar de que, "para público externo", possa parecer que é o indivíduo que está reinando, na realidade, aqui o "sujeito social" é o mercado. Evidentemente, tudo isto ocorre sob uma "naturalização" dos fatos. Para Marcuse, esse acontecimento atesta, sobretudo, que agora o capitalismo está colonizando o território da subjetividade humana, tendo como aliado às ciências da psique e também a cultura e a arte, em prol menos do despertar da consciência e mais do "homem unidimensional". (3.3) Marcuse, aqui, se aproxima muito do jovem Marx, especialmente do texto os Manuscritos Econômicos e Filosóficos, de 1832. Aqui, o jovem Marx aponta que a luta pela concretização do comunismo não se reduz apenas as preocupações de bases materiais e econômicas, mas deve buscar uma libertação completa do humano: trata-se da libertação da consciência e do inconsciente. Neste particular, está em questão também uma espécie de luta pela emancipação histórica que envolve tanto a razão quanto a sensibilidade. Esta caminha não só ao encontro de Marx e de Freud, mas também do estudo de questões da subjetividade. Isto não se reduz ao estudo da vida privada, no seu pior termo (tal como se fossemos, por exemplo, estudar a obra de Weber, para a explicarmos em função de ele ter sido ou não acometido por uma patologia na sua vida pessoal). Ora, se a unidimensionalidade, principalmente pela cultura e arte ajuda o atual capitalismo a colonizar a subjetividade para colocá-la exclusivamente em função de seus interesses, de outro lado, podemos fazer o inverso: desenvolver um trabalho nesse território subjetivo tanto para rediscutirmos o lado protagonista, quanto às ações históricas, a fim de colocar no centro do mundo o "homem emancipado" em vez do "homem unidimensional" (MARCUSE, 2001, 1981, 1973; HABERMAS, 1980; LOUREIRO, 2010). 


\section{Instituição, globalização e o homem unidimensional}

Para Lapassade (1977), o principal legado da análise institucional é fazer uma mediação entre o indivíduo e a realidade social, traduzindo-se por "três níveis principais de compreensão da sociedade", que são: o grupo, a organização e a instituição.

O grupo é base da ordem reinante e de nossa vida cotidiana. A ordem precisa dele, sobretudo, para se fazer presente por suas leis e normas. Socialmente, se somos inseridos através de diferentes agrupamentos, neles também nós nos "costuramos e somos costurados" ao estabelecido. Enfim, se o grupo é uma espécie de "cimento social" que fixa o sujeito ao conjunto de normas nas inserções grupais, ele é ainda o "iceberg" da ordem reinante. A título de exemplo, destacamos: há o grupo de alunos da UFRJ, de operários da fábrica CSN, de empresários da empresa "Daslu” de São Paulo e assim por diante.

Ora, se através desse dispositivo se dá a captura em prol da ordem vigente, de outro lado, sob outro contexto político, através do grupo também se traz à tona grande potencial de mudança. Aqui, em tese, se chocam duas forças poderosas que atravessam toda e qualquer instituição: referimo-nos a força instituída e a força instituinte ${ }^{6}$.

A “organização", segundo nível dessa mediação, faz uma ponte entre a sociedade civil e a cúpula do Estado. Caracterizando-se principalmente pelo aspecto burocrático, pensá-la é falar das funções de gerenciamento como um todo, tanto na área estatal quanto na privada. A organização, tratando do nível do estabelecimento administrativo, diz da retransmissão de ordens e também da administração, envolvendo uma política de papéis, inclusive sob as formas jurídicas. Evidentemente, trata-se de uma função significativa para o bom desempenho de qualquer instituição, contudo, há algumas considerações importantes a se pensar: a) ela não necessariamente precisa ser exercida de modo enfadonho, ou seja, referimo-nos ao lamentável instante em que se torna apenas um meio para interesses apequenados dos funcionários, levando ao carreirismo; b) ainda empregando a mesma palavra para falar da atividade administrativa e/ou burocrática, ela se exerce de duas maneiras: de um lado, com uma função na qual há profissionais que a realizam com primor, esforçandose para que a atividade fim da instituição se concretize realmente em prol dos usuários. Aqui tal fato se dá pelo exercício do trabalho com qualidade, mas sem reduzi-lo ao mero produtivismo. Mas, o oposto também ocorre, pois, infelizmente, neste caso, substitui-se a busca desse "trabalho com qualidade" pela burocracia-burocratismo: agora essa função é realizada na organização, mas obedecendo apenas aos interesses ultra-individualistas (BAREMBLITT, 1992).

Toda organização contém o estabelecimento, ou seja, o referido estabelecimento não só são as organizações que se manifestam por seus lados "micro-organizacionais", como também o fazem na realidade concreta. Assim, constatando que eles estão em diferentes lugares do tecido social, estamos falando do conjunto de "organizações ditas menores" que lá estão com seus endereços fixos (em prédios, casas etc.) na concretude da realidade social”. Enfim, se o Ministério da Educação, o Ministério da Saúde, o Ministério do Trabalho são exemplos de organização ou de agrupamentos maiores, de outro, a Universidade Federal do Rio de Janeiro, o Hospital Miguel Couto, a fábrica Companhia Siderúrgica Nacional (CSN), entre outros, são exemplos de estabelecimento.

A “instituição”, terceiro nível de mediação, tem múltiplas conceituações, mas aqui ela será discutida, de um lado, como o Estado (ALTHUSSER, 1980), e de outro, como a Transversalidade (GUATTARI, 1981; LAPASSADE, 1977) ${ }^{8}$.

Discutir a instituição como Aparelho Ideológico de Estado (AIE), de acordo com Althusser (1980), é principalmente pensar que para manter-se, o Estado capitalista necessita de um conjunto de agrupamentos, os quais tanto o sustenta quanto têm como função garantir sua produção, reproduzindo a sua ideologia dominante. Diante disto, a título de ilustração, esse "Estado" só pode existir se contar também com um conjunto de AIE, que são: a família, a escola, o hospital, a igreja e a assim por diante. "A escola (mas também outras instituições do Estado, como a igreja e outros aparelhos como o exército) ensina o know-how, mas sob formas que asseguram a submissão à ideologia dominante ou o domínio de sua prática" (ALTHUSSER, 1980, p. 58) ${ }^{9}$.

Debater a instituição como a Transversalidade, para Guattari (1986), sobretudo, é ampliar nosso entendimento sobre as relações de poder que nos rubricam. Tal rubrica se dá baseada no modelo de homem unidimensional que nos atravessa, principalmente de forma quase que imperceptível, através das relações individuais, dos grupos e até com o Estado no mundo globalizado. Em outras palavras, discutemse agora as relações transversais, as quais se traduzem pelo entrecruzamento de quatro linhas principais que gestam nosso comportamento, que são: a linha econômica, a linha ideológica, a linha política e também a do desejo. ${ }^{10} \mathrm{Em}$ síntese, isto significa o seguinte: (a) tal conceito aponta principalmente para o fato de que nosso comportamento social e pessoal é rubricado pelo entrelaçamento dessas linhas básicas que nos fazem ver, sentir e pensar, a rigor, de acordo com a hegemonia reinante. O detalhe, aqui, é que essa determinação não é só fruto de relações econômicas. Não que estas relações não tenham a sua importância devida, mas, sob tal perspectiva, há também outras linhas que se entrelaçando com a linha econômica, 
dependendo do contexto, têm também papel cabal nas instituições: referimo-nos a linha da política, da ideologia e também da produção do desejo. (b) O Estado tem sua importância, pois que, no conjunto das instituições sociais, é um dos que mais se destaca, figurando inclusive como uma "instituição gerente" diante do restante dos grupos institucionais (família, educação, saúde etc.). (c) Observe-se, contudo, que até esse "gerente maior" é atravessado pelo modo de vida da ordem vigente, o qual reproduz a ideologia e a subjetividade em prol do homem unidimensional. (d) Aparece aqui, agora, uma diferença com a visão que reduz a instituição apenas ao Estado: (d. 1) para Guattari, na globalização, o centro do poder se desloca do Estado (ou dos Estados nacionais), passando agora a um centro que tanto está à parte, quanto também dentro do sistema do poder. Desta forma, mesmo estando aparentemente "fora", tal centro controla e submete os diferentes Estados a sua política neoliberal. Ianni (2004), exemplificando, defende que, sob a atual globarbarização, elegemos um candidato inclusive com propostas ditas mais progressistas para abrir uma brecha contra o modelo neoliberal de Estado mínimo, mas, ao chegar ao poder, tal candidato reproduz o jogo hegemônico em nome da dita governabilidade e do consenso mundial das finanças. $\mathrm{Na}$ realidade, isto ocorre porque, diante da atual tendência mundial o foco central de poder está, sobretudo, na Santíssima Trindade do "deus mercado", que são: o FMI, o Banco Mundial e a OMC; (d. 2) a segunda diferença é que, pela metáfora da transversalidade temos um mapa aproximado de como o poder hegemônico se faz presente e também captura os diferentes desejos individuais, os grupos e os diferentes Estados pela globalização mercadológica. Traduzindo: mesmo diante disto, podemos criar políticas de resistência, as quais Marcuse denomina de contracultura na cultura preponderantemente capitalista; um movimento anti-institucional nas instituições hegemônicas, bem como políticas de subjetividades rebeldes frente à subjetividade hegemônica. Sim! Tudo isso, de forma alguma invalidará que tenhamos que nos articular com a política mais geral: é preciso que se faça a devida ponte com os partidos e as políticas partidárias, inclusive para se criar rupturas com a luta de classe ${ }^{11}$.

\section{Conclusões}

Este trabalho, baseado em Marcuse, aponta que o capitalismo, através da atual globalização mercadológica, além de ditar as condições materiais do homem, ocupa agora o território subjetivo. Assim, uma vez instalado na nossa subjetividade, a rigor, o indivíduo passa a desejar, olhar e pensar de acordo com esses valores em qualquer parte do mundo. Tal fato, além de tender a levar esse indivíduo a se identificar com um modo de vida consumista (principalmente inspirado nos produtos e marcas de grandes empresas), contraditoriamente estimula também um tipo de liberdade, a qual, reduzida apenas ao mercado, aponta para uma espécie de "servidão voluntária" a ordem hegemônica.

Esse "modelo" que atravessa o Estado e as instituições, capturando e reproduzindo os valores da ordem, recebe o nome aqui de o "Homem unidimensional". Marcuse critica esta "unidimensionalidade" por vários motivos, dentre eles, destacamos: o homem unidimensional, ao construir um suposto consenso globalizado, não admite qualquer diferença que faça realmente a diferença: isto se traduz não só no rechaço a tudo que "não lhe é espelho", mas também em se criar paradoxalmente os movimentos de "oposição" e de "liberdade". Detalhe: essa oposição e emancipação jamais poderão ultrapassar limites que ponham em risco os pressupostos do mercado. Essa "unidimensionalidade" se firma e se reproduz na atual globalização porque passa principalmente de forma implícita pela rede transversal de poder hegemônico: através da família, da fábrica, da empresa, da escola, da universidade; das diferentes igrejas, dos diferentes Estados e assim por diante.

Resistência? Que resistência? Esta é a grande questão de Marcuse frente a essa "unidimensionalidade". Assim, em resumo, o artigo aponta: por maior que seja a pretensão totalitária desse atual modelo, criando um suposto consenso que exclui toda diferença, essa hegemonia não reina absoluta: há espaços, existem brechas dentro das instituições sociais, as quais, a partir daí poderão advir à resistência. Daí que é necessário ousar a existir em minoria e também ir cotidianamente acumulando forças no trabalho de "formiguinha", criando condições para que, sempre que possível, surja um movimento de ruptura e de lutas anti-institucionais específicas e concretas contra a hegemonia vigente ${ }^{12}$. Observe-se que ao se propor movimentos de resistências anti-institucionais e de questões específicas, Marcuse não desqualifica a política mais geral, inclusive articulada a organização de segmentos e também aos partidos, preferencialmente de esquerda, pois que visam, em última instância o fim do capitalismo. Não adianta querer mudar a sociedade apenas por lutas institucionais específicas, por mais que elas sejam concretas e justas, tais como são, por exemplo, as lutas antimanicomiais, as lutas pelo "passe livre" etc. Enfim, se elas ficarem restritas apenas ao território de suas especificidades e não tiverem a devida articulação com os movimentos políticos e partidários haverá grandes chances de fracassarem. 
Marcuse agora chama a atenção para um detalhe importante: todo esse esforço tenderá ao fracasso não só se não o articularmos a atividade política mais geral, mas também - e em especial - a questão das lutas de classe. Sim! Mesmo admitindo que nada de errado há em se pensar as lutas específicas, cotidianas e singulares que envolvem inclusive o campo da vida privada e da subjetividade; ainda chamando a atenção que tal "campo" precisa estar articulado a política mais geral e inclusive partidária, desconsiderando esta última conclusão, estaremos caindo no erro de estarmos acariciando os próprios grilhões. Enfim, negando a luta de classe, não só estaremos subscrevendo nossa própria prisão, como também virando as costas para uma ferramenta de vital importância que poderá nos emancipar e criar a nova ordem socialista. Desta maneira, o que caracteriza Marcuse de outros pensadores, os quais estudam a subjetividade é o seguinte: malgrado a forma que a pensemos (subjetividade, institucionalismo, homem unidimensional, rede transversal de instituições etc.), nada disto se sustenta se não houver a devida articulação com a luta de classe. Basta recordar que, para ele, se é preciso romper com esse afeto equivocado pelos "próprios grilhões" (alimentado às vezes pela subjetividade hegemônica), é impossível a emancipação se desconsiderarmos essa questão da classe. Aliando tais lutas às distintas maneiras de se ver a subjetividade, em síntese, nós construiremos a "verdadeira imagem do futuro" emancipado, mas pelo combate as instituições hegemônicas a partir de hoje.

\section{Referências}

ALTHUSSER, L. Aparelhos ideológicos de Estado. Tradução de Walter José Evangelista e Maria Laura Viveiros de Castro. Rio de Janeiro: Graal, 1980.

ANTUNES, R. Adeus ao trabalho? São Paulo: Cortez, 2003.

BAREMBLITT, G. F. Compêndio de análise institucional e outras correntes: teoria e prática. Copydesk: Renato Rosário Carvalho. Revisão: Maria Thereza Duarte, João Henrique de Assis Machado, Cristina Possidente, Antonio dos Prazeres. Rio de Janeiro: Rosa dos tempos, 1992.

BENJAMIN, W. Gesammelt Schriften. Frankfurt: Suhrkamp, 1998. (v. 1).

BOTTOMORE, T. Dicionário do pensamento marxista. Tradução de Waltensir Dutra. Rio de Janeiro: Zahar, 1988.

EAGLETON, T. Marx estava certo. Tradução de Regina Lyra. Rio de Janeiro: Nova Fronteira, 2012.

GORZ, A. Metamorfoses do trabalho: crítica da razão econômica. Tradução de Ana Montóia. Rio de Janeiro: Annablume, 2003.

GUATTARI, Félix. Revolução molecular. São Paulo: Brasiliense, 1981.

Micropolíticas: cartografias do desejo. Petrópolis: Vozes, 1986.

GUIRADO, M. Psicologia institucional. São Paulo: EPU, 1987.

HABERMAS, J. Arte e revolução em Herbert Marcuse. In: FREITAG, B.; ROUANET, P. S. (Org.). Habermas: sociologia. São Paulo: Ática, 1980.

HARVEY, D. Condição pós-moderna. Tradução de Adail Ubirajara Sobral e Mara Stela Gonçalves. São Paulo: Loyola, 2007.

IANNI, O. Capitalismo, violência e terrorismo. Rio de Janeiro: Civilização Brasileira, 2004.

LAPASSADE, G. Grupos, organizações e instituições. Tradução de Henrique Augusto de Araújo Mesquita. Rio de Janeiro: Francisco Alves, 1977.

LIPOVETSKY, G. A felicidade paradoxal: ensaio sobre a sociedade de hiperconsumo. Tradução de Maria Lúcia Machado. São Paulo: Companhia das Letras, 2007.

LOUREIRO, I. Herbert Marcuse: anticapitalismo e emancipação. Disponível em: <http://www.scielo.br/scielo.php?pid=S010131732005000200001\&script=sci_arttext\#end03>. Acesso em: 20 mar. 2010.

MARCUSE, H. Idéias sobre uma teoria crítica da sociedade. Tradução de Fausto Guimarães. Rio de Janeiro: Zahar, 1972. . Contra-revolução e revolta. Tradução de Álvaro Cabral. Rio de Janeiro: Zahar, 1973.

. Eros e civilização. Uma interpretação filosófica do pensamento de Freud. Tradução de Álvaro Cabral. Rio de Janeiro: Zahar, 1981.

A ideologia da sociedade industrial: o homem unidimensional. Tradução de Giasone Rebuá. Rio de Janeiro: Zahar, 1982.

Tecnologia, guerra e fascismo. Tradução de Maria Cristina Vidal Barbosa. São Paulo: Unesp, 1999.

Cultura e psicanálise. Tradução de Wolfgang Leo Maar, Isabel Loureiro e Robespierre de Oliveira. Rio de Janeiro: Zahar, 2001a. . A noção do progresso à luz da psicanálise. In: MARCUSE, H. Cultura e psicanálise. Tradução de Wolfgang Leo Maar, Isabel Loureiro e Robespierre de Oliveira. Rio de Janeiro: Zahar, 2001b.

PISANI, M. M. Utopia e psicanálise em Marcuse. Trans/Form/Ação, Marília, v. 29, n. 2, p. 203-217, 2006.

. Algumas considerações sobre ciência e política no pensamento de Herbert Marcuse. Sci. Stud., São Paulo, v. 7, n. 1, p. 135-158, 2009. Disponível em: 〈http://www.scielo.br/pdf/ss/v7n1/v7n1a07.pdf>. Acesso em: 17 set. 2012.

ROUANET, S. P. Teoria crítica e psicanálise. Rio de Janeiro: Tempo Brasileiro, 1986.

SOUZA, A. de. Marcuse e ofim da sociedade de trabalho. Disponível em: <http://www.consciencia.org/marcusemichel.shtml >. Acesso em: 20 mar. 2010. 


\section{Notas}

1 Nesse ponto, há um paralelo com outro estudo, o qual aponta que para se viver a Jerusalém prometida, mas já a partir da terra, ao nos submetermonos as diferentes mídias, a propaganda e ao marketing, vive-se o seguinte slogan: “Sofro...? Logo consumo!” (LIPOVETSKY, 2007).

2 Essa parte do trabalho, além dos livros de Marcuse (1982, 1972, 1999), contou também com o apoio de outros textos: Rouanet (1986), Pisani (2006, 2012), Souza (2010).

3 Essa crítica de Marcuse nãoé contra os ganhos da tecnologia. Ao contrário, apenas se opõe frontalmente que eles fiquem unicamente a serviço de uma ordem que privilegia mais os lucros do que o bem estar e até a própria vida humana. Quanto a isto, a propósito, o movimento do Ocupy que começou a partir da última crise de quebradeira do capitalismo tem um slogan que ilustra bem tal fato: temos que buscar o crescimento tecnológico e econômico não para $1 \%$, mas sim para $99 \%$ da população mundial.

4 Essa forte tendência totalitária da sociedade unidimensional, também pode ser ilustrada através da questão da oposiçãoe da considerada liberdade de expressão nas diferentes mídias. Ora não que sob a ordem unidimensional atual não exista oposição e nem mídias ditas livres; entretanto, há aqui um detalhe a ser desvendado: a oposição e as mídias neste mundo globalizado, obviamente trazem sua contribuição ao debate e, sob certos contextos, criam seu estrondo na sociedade civil, porém tudo isso dentro de limites bem claros: elas, de forma alguma, farão qualquer procedimento que venha pôr realmente em risco os pressupostos da globalização unicamente sob a esteira da economia do mercado.

5 Obviamente, para Marcuse, cultura e arte tem sua distinção. A ponto de que, por exemplo, em sua obra, o filósofo escreve um particular texto marcando essa distinção e tratando o tema da arte junto à possível potencial revolucionário: “Arte e revolução" (MARCUSE, 1973). Contudo, neste instante, estamos apresentando esses dois fatores juntos, sobretudo, no sentido de que, do ponto de vista do olhar do "homem unidimensional", há grande interesse em se fundir a cultura e a arte, principalmente com vistas a reduzi-las unicamente aos negócios rentáveis.

6 De acordo com Guirado (1987), as forças instituídas têm relação com a manutenção da ordem hegemônica. Elas não só funcionam em prol do estabelecido como também tendem a reprimir e limitar tudo e todos que, por ventura, possam pôr em risco a ordem. As forças instituintes, de outro lado, além de serem forças totalmente opostas às instituídas e estarem sendo constantemente combatidas por elas, quando vem à tona trazem grande potencial de ruptura. Há aqui um detalhe: o que é hoje instituído, amanhã pode vir a se tornar instituinte e, portanto, a pior compreensão sobre esses conceitos é vê-los sob visão cristalizada e meramente maniqueísta: “o instituído é o bem” e o "instituinte é o mal”. Ao contrário disto, se possível, devemos observá-los de visão processual e dialética.

7 Oestabelecimento está contido na organização e não deve ser confundido com a instituição: a instituição, além de nos atravessar pelos diferentes grupos, exercendo sobre nós sua regulação para que se tenha uma forma própria de se ver a vida, ela se situa no terceiro nível de mediação social, que é um território subjetivo e abstrato; por sua vez, o estabelecimento, afora ser uma espécie de aparelho menor da organização, não só está no segundo nível, como também se situa no plano material. Daí que, para alguns, dado essa materialidade, ele até poderia ser designado como um sistema de "instituições externas" (LAPASSADE, 1977).

8 Na realidade, cabe a Guattari $(1981,1986)$ a autoria do conceito de Transversalidade. Naárea de análise institucional, houve uma apropriaçãoe um grande desenvolvimento desse conceito por Lapassade; contudo, malgrado isto, neste trabalho, vamos discutir esse conceito apenas dando crédito ao seu autor.

9 Além do AIE, diz-nos ainda Althusser, o Estado se sustenta pelo ARE (Aparelho Repressivo do Estado), que corresponde à polícia e o exército. Aqui, em síntese, tem relação com o seguinte: (1) quando o indivíduo, sob a sociedade capitalista, não se convence pela persuasão do AIE, entra em cena a repressão, quer dizer, chama-se o ARE. (2) Como há interação entre esses dois “aparelhos”, o autor em questão diz que não existe, portanto, aparelho puramente ideológico e nem unicamente repressivo.

10 Ainstituição pode também ser discutida como uma forma de regulamentação básica de nossas vidas. Tal "regulamentação" que é entrelaçada por diferentes determinações que subscrevem nossas relações e não se reduz apenas a fatores econômicos, pode ser traduzida também por um significante social. Este "significante", de um lado, em primeiro lugar é uma lei simbólica, mas depois tem seu correlato na vida concreta pelas normas e leis que se atravessam pelas organizações, estabelecimentos e grupos. O curioso é que tal procedimento se faz valer tanto por "acordos não escritos", quanto por escritos formalmente (normas e leis jurídicas formais), contudo, no fundamental, eles regulam nossas existências. Assim, não éá toa que, de forma geral, a instituição é compreendida por tudo aquilo que se instituie está instituído na sociedade. Em outras palavras, tratase de uma instância de enunciação, a qual, malgrado estar relacionada à lei simbólica e/ou as normas jurídico-formais, regula a nossa vida coletiva e pessoal e é determinada por diversos fatores: fatores econômicos, políticos, ideológicos e também aos do desejo singular de cada indivíduo. Basta lembrar que se esse indivíduo está ou não aderindo a tal instância de enunciação ou ao significante hegemônico, há um desejo aí preponderando, o qual se entrelaça ao território subjetivo e inconsciente. Desnecessário apontar ainda que, sob o atual sistema capitalista, a instituiçãoé uma grande aliada da ordem hegemônica.

11 (a) "Classe" é conceito interessante, pois, para Bottomore (1988), afora Marx e Engels não o terem pensado de forma sistematizada, a "luta de classe" é significativa para o marxismo. Ela inspirou Marx tanto a ver o proletário como nova força política que emancipa toda a humanidade, quanto também a estudar a estrutura econômica para se criar uma ruptura contra a exploração do capitalismo; (b) Diante desta globalização, se há autores, como Gorz (2003), defendendo que não há mais a classe operária, Harvey (2007) argumenta que essa “classe” está mais viva do que nunca e também se expandiu, aumentando seu potencial de ruptura. Assim, para Marcuse (1982), Eagleton (2012), Antunes (2003), trata-se de vê-la através de trabalhadores que estão nas fábricas, mas também no campo, nos serviços terceirizados; entre os pequenos comerciantes, os professores, os funcionários públicos e privados, bem como todos os grupos de trabalhadores que sobrevivem de seu próprio trabalhado: eles não são proprietários dos meios de produção, nem vivem de aplicações e rendas do acúmulo do capital; (c) o importante aqui, para Marcuse, é que o potencial de ruptura de tal "classe" para superar o capitalismo, agora se expandiu e, em certos momentos históricos, tal como em Maio-68, em Paris, ou em Junho-2013, no Brasil, pode-se até ter o apoio dos estudantes. 
12 O Movimento do Passe Livre/SP (MPL) é um dos exemplos, o qual, mesmo sendo minoritário e anticapitalista, ousou manter a luta pela "tarifa zero" em São Paulo cujo contexto é neoliberal. Enfim, questionando as instituições de transportes, lutando contra os "vinte centavos" das passagens, o MPL trouxe à tona o potencial de contestação dos brasileiros, o qual estava capturado pelos últimos governos alinhados com a globalização mercadológica; inclusive por governos que se diziam mais a esquerda do que o de FHC.

\section{Rogério Lustosa Bastos}

rogerlustosa6@gmail.com

Pós-Doutor em Psicanálise pela Universidade do Estado do Rio de Janeiro (UERJ)

Doutor em Psicologia pela Pontifícia Universidade Católica de São Paulo (PUC-SP)

Professor da Escola de Serviço Social da Universidade Federal do Rio de Janeiro (UFRJ)

UFRJ - Escola de Serviço Social

Av. Pasteur, 250

Campus da Praia Vermelha

Rio de Janeiro - Rio de Janeiro - Brasil

CEP: 22290-240 